\title{
Teaching Nutrition in the Context for Lifestyle Medicine
}

\author{
Robert F. Kushner ${ }^{1} \cdot$ Linda Van Horn ${ }^{2}$ \\ Published online: 26 July 2018 \\ (C) International Association of Medical Science Educators 2018
}

\section{Introduction}

Lifestyle Medicine is a nascent discipline that has recently emerged as a central approach for management of chronic disease $[1,2]$. The individual elements and skillsets that define Lifestyle Medicine are determined, in large part, by the primary contributors to non-communicable diseases (NCD). Unhealthy lifestyle behaviors are among the leading risk factors for increased disability-adjusted life years (DALYs) in the USA [3] and around the world [4]. The World Health Organization (WHO) published the 2008-2013 Action Plan for the Global Strategy for the Prevention and Control of Noncommunicable Diseases to prevent and control the 4 NCDs-cardiovascular diseases, diabetes, cancers, and chronic respiratory diseases and the 4 shared risk factorstobacco use, physical inactivity, unhealthy diets, and the harmful use of alcohol [5]. These NCDs are preventable. Additionally, the 4 associated risk factors/individual lifestyle behaviors are among the 5 multiple determinants of health as defined by Healthy People 2020, the science-based, 10-year national objectives for improving the health of all Americans [6]. The other 4 determinants are environment, social, health care, and genetics and biology. To better prepare medical trainees for the prevention and management of NCDs, published competencies in lifestyle medicine facilitate application of the principles taught in the medical curriculum $[7,8]$.

Diet and nutrition play a predominant role in Lifestyle Medicine and are thus recommended for inclusion across the curriculum. Opportunities for integration of nutrition in

Robert F. Kushner

rkushner@northwestern.edu

1 Division of Endocrinology, Department of Medicine, Northwestern University Feinberg School of Medicine, 645 North Michigan Avenue, Suite 530, Chicago, IL 60611, USA

2 Department of Preventive Medicine, Northwestern University Feinberg School of Medicine, Chicago, IL, USA undergraduate medical education (UME) [9] and competencies for medical nutrition education [10] have been published. The purpose of this article is to briefly review the approach taken by the Northwestern University Feinberg School of Medicine (NUFSM) to incorporate nutrition into a Lifestyle Medicine thread. The report focuses on our Phase 1 experience encompassing the first 2 years of medical school. We also summarize existing versus evolving nutrition education content in a more broader context.

\section{Incorporation of Nutrition into Lifestyle Medicine in an Undergraduate Medical Education Curriculum}

In 2010, NUFSM launched a redesign of its UME curriculum, with the first class matriculating in 2012 [11]. Lifestyle Medicine was designated as one of five essential threads and incorporates key practices that are associated with maintenance of health and prevention and treatment of disease. The eight components selected were nutrition, physical activity, smoking, substance use, sleep, stress, behavior change, and body weight. Each component is incorporated horizontally and longitudinally throughout the curriculum and is strategically integrated into each of the 13 organ-based system modules over the first 2 years. In the new curriculum, all aspects of medicine, e.g., normal physiology, pathophysiology, imaging, clinical care, etc., are taught simultaneously within the same module as they relate to a specific organ system such as cardiovascular, pulmonary or renal. For this article, we reviewed all student learning guides for lifestyle medicine content from Phase 1 for the academic year 2016-2017.

During Phase 1, the eight components of the Lifestyle Medicine thread were identified 462 times within 268 session learning guides, of which 78 (29\%) sessions addressed some aspect of diet and nutrition. Figure 1 displays the distribution of diet and nutrition across the 13 organ-based system modules. As seen, the largest number of sessions on diet and nutrition were presented during the foundation (FND), 
Fig. 1 Distribution of diet and nutrition content across the phase 1 modules by number of sessions

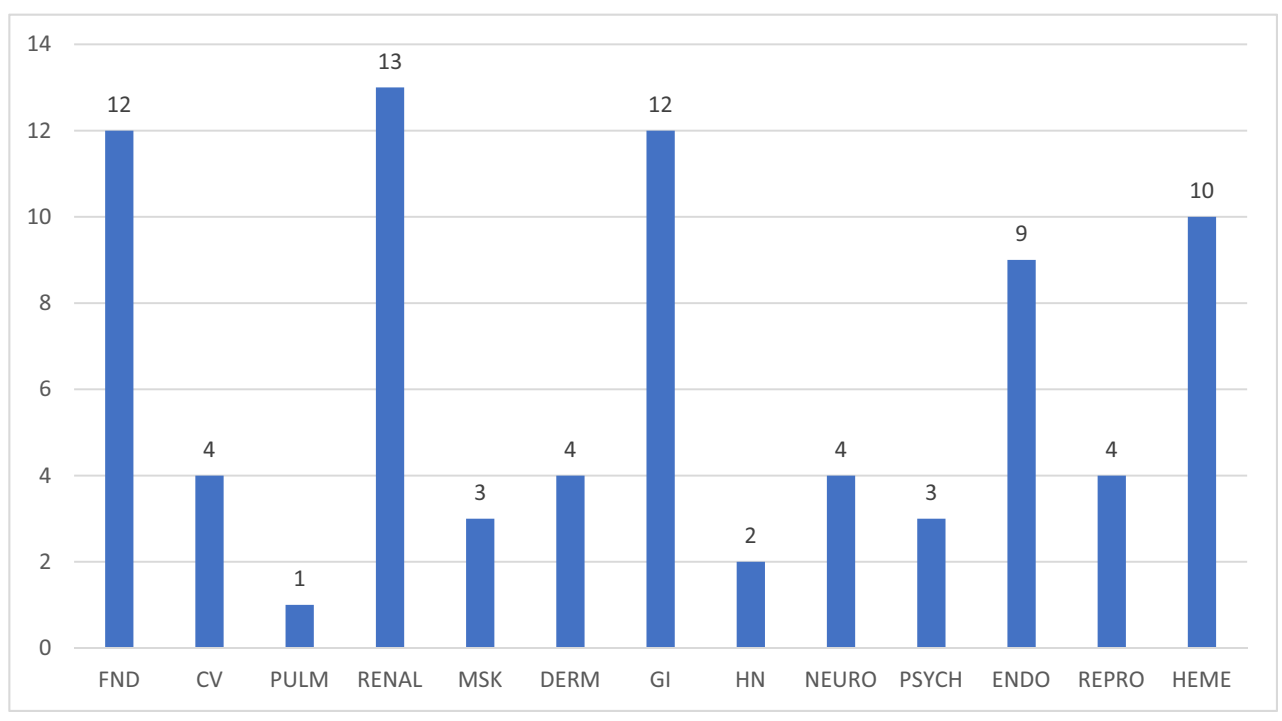

renal, gastroenterology (GI), endocrinology, (ENDO), and hematology/oncology (HEME) modules.

Table 1 specifies diet and nutrition content and the corresponding number of sessions presented during each of the modules. The keypoint of the integrated curriculum is that stage-appropriate content is distributed across the modules depending upon its organ-based system relevance. For example, minerals and water balance are addressed during the renal module, micronutrient and macronutrient absorption is presented in the gastroenterology
Table 1 Distribution of diet and nutrition related topics and number of sessions for each of the 13 organ-based system modules

\begin{tabular}{|c|c|c|}
\hline Module & Topic & Number of sessions \\
\hline Foundation & $\begin{array}{l}\text { US Dietary Guidelines Advisory Committee } \\
\text { review of Diet, behavior change, counseling, } \\
\text { public policy, dietary counseling with } \\
\text { Standardized patient }\end{array}$ & 12 \\
\hline CVD & $\begin{array}{l}\text { Nutrition (dietary fatty acids SFAs, added } \\
\text { sugars and TG's, HDL, dietary fiber), CVD, } \\
\text { hyperlipidemia, hypertension (sodium/ } \\
\text { potassium DASH/Mediterranean diet pat- } \\
\text { terns) coagulation }\end{array}$ & 4 \\
\hline Pulmonary & Cystic fibrosis & 1 \\
\hline Renal & $\begin{array}{l}\text { Minerals (calcium, phosphorus) and } \\
\text { hemodialysis; water balance, salt and } \\
\text { hypertension, CKD and protein }\end{array}$ & 13 \\
\hline Musculoskeletal & Bone development & 3 \\
\hline Dermatology & Vitamin D & 4 \\
\hline Gastroenterology & $\begin{array}{l}\text { Micronutrient absorption } \\
\text { Absorption of water and electrolytes } \\
\text { Lipid digestion and absorption } \\
\text { malabsorption }\end{array}$ & 12 \\
\hline Head and neck & Vitamin A & 2 \\
\hline Neurology & Dietary triggers of headache, taste and smell & 4 \\
\hline Psychiatry & Eating disorders & 3 \\
\hline Endocrinology & $\begin{array}{l}\text { Appetite regulation, metabolism, obesity, } \\
\quad \text { diabetes, malnutrition } \\
\text { Pediatric obesity (diet) } \\
\text { Obesity counseling (diet) }\end{array}$ & 9 \\
\hline Reproduction/genitourinary & Pregnancy, lactation, menopause & 4 \\
\hline Hematology/oncology & Vitamin $\mathrm{B}_{12}$, folate, iron and anemias & 10 \\
\hline
\end{tabular}


module, and appetite and energy regulation are covered during the endocrinology module. Collectively, $70 \%$ of all Lifestyle Medicine thread content is presented in the "Science in Medicine" element of the curriculum, emphasizing the importance of scientific-based knowledge during the first 2 years of medical school.

An additional unique feature of the Lifestyle Medicine thread is the Behavior Change Plan (BCP), a 6-week activity conducted during the Foundation module where students have the opportunity to learn the process of making a selective behavior change, appreciate the challenges in implementing change, learn a skill that is useful in the clinical care of patients, and improve their own health [12]. The BCP directly addresses "Personal Awareness and Self-Care," one of the 8 competencies that guide the NUFSM curriculum. Approximately one fourth of students select diet for their BCP, compared to $45 \%$ who select physical activity and exercise. For the culmination of the activity, students present their $\mathrm{BCP}$ in a small group setting.

Assessment of Lifestyle Medicine is primarily conducted through multiple choice examinations, with lesser number of assessments via small group discussions and objective structured clinical examinations (OSCE).

\section{Summarizing Existing Versus Evolving Nutrition Education Content}

Nutrition is an ever-evolving science and medical nutrition education requires ongoing updates of the evidencebased research that underlies dietary guidance and recommendations for both population-wide prevention and patient-specific therapy. As described above, knowledge of basic nutrition principles, food sources of nutrients, and diet assessment approaches are key to interpreting and applying these principles and are relevant across the entire medical nutrition curriculum [10]. Regardless of whether the content is incorporated into a Lifestyle Medicine thread or presented in a difference educational format, fundamental nutrition topics summarized by the Institute of Medicine (IOM) and National Academy of Sciences include: [13].

\section{Macronutrients: Recommended Intake Ranges, and Diet Composition}

Calorie requirements and energy balance

- Fatty acids and sterols; carbohydrates and fiber; amino acids and proteins;

- Vitamins, minerals, trace elements, and electrolytes
- The basic roles of all of these in human metabolism and homeostasis

Developing competencies in diet counseling to address these topics requires further adaptation. For example, diet counseling for prevention and treatment of cardiovascular diseases further requires:

- Knowledge of food sources of nutrients to be translated into practical healthy eating applications including: healthy-unhealthy fats, whole grains, lean animal and plant proteins, sterols, and flavonoid-rich fruits, green leafy and other vegetables, including those with roles in regulating oxidative stress, [14] and as documented in the USDA food composition database [15] Likewise, underconsumed nutrients, including calcium, potassium, dietary fiber, and vitamin $D$, and their food sources are highlighted as documented by the US Dietary Guidelines Advisory Committee Report based on the DGAC [15]

- Knowledge of food sources to limit/avoid include: foods with added sugars, sodium, and saturated and trans-fats in processed foods and beverages and clarifying consumer confusion regarding high fiber but sugar-laden cereals, granola bars, yogurts, non-dairy "milks" and fruit "juices"; salt-laden vegetables, juices, breads and cereals; coconut-oil, processed meats, fried fish

- Knowledge of the updated federally mandated Nutrition Facts label and its application is also recommended [16].

- Knowledge of evidence regarding dietary supplements and specifically related to omega-3-fatty acids and other popular but not well-documented supplements should be applied as appropriate [17, 18].

- Knowledge of diet assessment methodology and tracking tools to both assess clinically and recommend self-monitoring including emerging mobile options such as MyFitnessPal [19] and Lose It [20] are relevant to diet counseling.

- Knowledge of popular weight loss diets and their pros/ cons regarding unintended consequences regarding risk factors for chronic diseases [21].

- Knowledge of the effects of food habits and environments on diet quality including patients with food insecurities and lower SES [22, 23].

Finally, the importance of integrating the broader health systems into patient care is emphasized. Specifically, students learn how to refer patients to local registered dietitians/ nutritionists (RDNs), diabetes educators, clinical lipid specialists, and obesity treatment experts; as well as to local programs that promote cooking skills, weight loss, diabetes prevention, and wellness; and to federal nutrition assistance programs, including the Women, Infants and Children (WIC) program, Meals-on-Wheels, and SNAP-Ed. 


\section{Conclusion}

Learners of the twenty-first century must have competence in the multiple components of lifestyle medicine for the prevention and treatment of NCDs. Embedding knowledge of diet and nutrition along with translational and behavioral competencies relevant to counseling within the context of a Lifestyle Medicine thread emphasizes the comprehensive approach needed to guide individuals toward living a healthy life. Examples of diet and nutritional content specific to cardiovascular disease have been delineated and available for incorporation into medical curricula.

\section{Compliance with Ethical Standards}

Conflict of Interest The authors declare that they have no conflict of interest.

Ethical Approval Ethical approval is not applicable in this study.

Informed Consent Informed consent is not applicable in this study.

\section{References}

1. Mechanick, JI, Kushner RF, Eds. Lifestyle Medicine: a manual for clinical practice. Springer, Publ, NY, 2016.

2. Kushner RF, Mechanick JI. Lifestyle medicine - an emerging new discipline. US Endocrinology. 2015;11(1):36-40.

3. Burden US. Of diseases collaborators. The state of US health, 19902010. Burden of diseases, injuries, and risk factors. JAMA. 2013;310(6):591-608.

4. Lim SS, Vos T, Flaxman AD, Danaei G, Shibuya K, Adair-Rohani $\mathrm{H}$, et al. A comparative risk assessment of burden of disease and injury attributable to 67 risk factors and risk factor clusters in 21 regions, 1990-2010: a systematic analysis for the Global Burden of Disesae Study 2010. Lancet. 2012;380:2224-163.

5. 2008-2013 action plan for the global strategy for the prevention and control of noncommunicable diseases: prevent and control cardiovascular diseases, cancers, chronic respiratory diseases and diabetes. World Health Organization 2008. WHO document production services, Geneva, Switzerland.

6. Healthy People 2020. http://www.healthypeople.gov/ (accessed February 22, 2015).

7. Lianov L, Johnson M. Physician competencies for prescribing lifestyle medicine. JAMA. 2010;304(2):202-3.
8. Hivert MF, Arena R, Forman DE, Kris-Etherton PM, McBride PE, Pate RR, et al. A scientific statement from the American Heart Association. Medical training to achieve competency in lifestyle counseling: an essential foundation for prevention and treatment of cardiovascular diseases and other chronic medical conditions. Circ. 2016;134:e308-27.

9. Kushner RF, Van Horn L, Rock CL, Edwards MS, Bales CW, Kohlmeier M, et al. Nutrition education in medical school: a time of opportunity. Am J Clin Nutr. 2014;99(suppl):1167s-73s.

10. Aspry KE, Van Horn L, Carson JS, Wylie-Rosett J, Kushner, $\mathrm{RF}$, et al. A Science Advisory from the American Heart Association. Medical nutrition education, training, and competencies to advance guideline-based diet counseling by physicians. Circ 2018 (published online).

11. Heiman HL, O'Brien CL, Raymond H. Curry RH, Green MM, Baker JF, Kushner RF, Thomas JX, Corbridge TC, Corcoran JF, Hauser JM, Garcia PM. Description and early outcomes of a comprehensive curriculum redesign at the Northwestern University Feinberg School of Medicine. Acad Med 2018: 93(4):593-599.

12. Kushner RF, Kessler S, McGaghie WC. Using behavior change plans to improve medical student self-care. Acad Med. 2011;86(7):901-6.

13. IOM Dietary reference intakes. Available at: https://www.nap.edu/ $\mathrm{read} / 10490 /$ chapter/1\#vi

14. Santhakumar AB, Bulmer AC, Singh I. A review of the mechanisms and effectiveness of dietary polyphenol in reducing oxidative stress and thrombotic risk. J Human Nutr Diet. 2013; https://doi. org/10.1111/jhn. 1217 .

15. USDA Food composition database. Available at: https://ndb.nal. usda.gov/ndb/

16. FDA Food Labeling: Available at: http://www.fda.gov/Food/ GuidanceRegulation/GuidanceDocumentsRegulatoryInformation/ LabelingNutrition/ucm385663.htm\#highlights.

17. NIH Food Supplement Database. Available at https://ods.od.nih.gov/

18. Siscovick, D, Barringer, TA and Fretts, AM et al. Omega 3 PUFA supplementation for the prevention of clinical cardiovascular disease: A scientific statement from the AHA Circulation 2017:135: https://doi.org/10.1161/CIR.0000000000000482.

19. Available at: https://www.myfitnesspal.com/

20. Available at: https://www.loseit.com/how-it-works/

21. Jensen et al. 2013 AHA/ACC/TOS guideline for the management of overweight and obesity in adults: a report of the American College of Cardiology/American Heart Association Task Force on Practice Guidelines and The Obesity Society. Circulation 2014;129(Suppl 2):S102-S138.

22. Dubowitz T, Zenk SN, Ghosh-Dastidar B, Cohen DA, Beckman R, Hunter $\mathrm{G}$, et al. Healthy food access for urban food desert residents: examination of the food environment, food purchasing practices, diet and BMI. Public Health Nutr. 2015;18(12):2220-30.

23. Coleman-Jensen A, Rabbitt M, Gregory C, Singh A. Household food security in the United States in 2015. USDA Economic Research Service Report Summary, June 2016. 